\title{
Debate on: Bracing in Adolescent Scoliosis Trial (BrAIST) - will the expenditure pay? HR Weiss
}

Address: Orthopedic Rehabilitation Services Alzeyer Str. 23 D-55457 Gensingen, Germany

Email: HR Weiss - hr.weiss@koob-scolitech.com

from 6th International Conference on Conservative Management of Spinal Deformities Lyon, France. 21-23 May 2009

Published: 14 December 2009

Scoliosis 2009, 4(Suppl 2):O43 doi:I0.II86/I748-7|6I-4-S2-O43

This abstract is available from: http://www.scoliosisjournal.com/content/4/S2/O43

(c) 2009 Weiss; licensee BioMed Central Ltd.

Adolescent idiopathic scoliosis has been regarded as a disease of relatively benign character without disastrous effects on the individual's health [1].

Therefore, treatment indications can be primarily regarded as aiming to achieve psychological and cosmetic benefits for the patient [2]. In fact, level II evidence has been established for conservative treatment [3], while there is no evidence of higher level for operative treatment $[4]$, and the real existing risks of surgery have not yet been clearly defined [5-7].

A five-year, $>\$ 5$ million project is being funded by the United States National Institutes of Health, the Canadian Institute of Health Research, and other international spine centers. Although a randomization protocol can only be scientifically used in standardized and therefore comparable treatments and conditions, this study design has been chosen to follow-up patients with scoliosis. Neither the condition, with a variety of different curve patterns, curve stiffness, and different stages of maturity (even when the data show agreement), nor the braces of different standards and different approaches, can be standardized satisfactorily. Therefore, the RCT is not at all the appropriate protocol for attempting to answer the proposed question. Of course, RCTs offer the highest evidence, but only if the design can be estimated as being appropriate, and for this population it is not.

There is already evidence on a high level for bracing, and to expose the control population of this study to the high risks of surgery, in case the scoliosis progresses to an extent with which the patient cannot comply, seems rather negligent. Even more, when one considers (1) the high risks of surgery [5-7], (2) that there will be no guarantee for improvement of the clinical condition [8], and (3) that health related problems can neither be solved nor prevented by surgical treatment $[5,9]$, this study from the patient's perspective seems a risky endeavor.

How reliable can a scientific society be regarded, whose members do not believe in a prospective controlled study on bracing they have established themselves [10] and at the same time can go ahead with surgical treatment, which scientifically raises more questions than it can provide answers?

Last but not least, a measure for brace quality was not initially included in the study protocol! So with whatever strict or not strict inclusion criteria, if the subject (brace) investigated in a RCT cannot be clearly defined, the outcome of that study will say one thing: nothing at all!

\section{References}

I. Asher MA, Burton DC: Adolescent idiopathic scoliosis: natural history and long term treatment effects. Scoliosis 2006, I(I):2.

2. Weiss HR, Bess S, Wong MS, Patel V, Goodall D, Burger E: Adolescent idiopathic scoliosis - to operate or not? A debate article. Patient Saf Surg 2008, 2(I):25.

3. Weiss HR, Goodall D: Treatment of Adolescent Idiopathic Scoliosis (AIS) according to present evidence - a systematic review. Eur J Phys Rehabil Med 2008, 44(2): 177-93.

4. Weiss HR: Adolescent Idiopathic Scoliosis - an indication for surgery? A systematic review. Disability \& Rehabilitation 2008, 30(10):799-807. 
5. Hawes M: Impact of spine surgery on signs and symptoms of spinal deformity. Pediatr Rehabil 2006, 9(4):3 I8-39.

6. Weiss HR, Goodall D: Rate of complications in scoliosis surgery - a systematic review of the Pub Med literature. Scoliosis 2008, 3:9.

7. Weiss HR: Is there a body of evidence for the treatment of patients with Adolescent Idiopathic Scoliosis (AIS)? Scoliosis 2007, 2:19.

8. Weiss HR: Adolescent Idiopathic Scoliosis - case report of a patient with clinical deterioration after surgery. Patient Saf Surg 2007, I:7.

9. Hawes MC, O'Brien JP: A century of spine surgery: what can patients expect? Disabil Rehabil 2008, 30(10):808-17.

10. Dolan LA, Donnelly MJ, Spratt KF, Weinstein SL: Professional opinion concerning the effectiveness of bracing relative to observation in adolescent idiopathic scoliosis. J Pediatr Orthop 2007, 27(3):270-6.

Publish with Bio Med Central and every scientist can read your work free of charge

"BioMed Central will be the most significant development for disseminating the results of biomedical research in our lifetime. "

Sir Paul Nurse, Cancer Research UK

Your research papers will be:

- available free of charge to the entire biomedical community

- peer reviewed and published immediately upon acceptance

- cited in PubMed and archived on PubMed Central

- yours - you keep the copyright

Submit your manuscript here:

http://www.biomedcentral.com/info/publishing_adv.asp 